\title{
B-Adrenergic Over-Stimulation and Cardio-Myocyte Apoptosis: Two Receptors, One Organelle, Two Fates?
}

\author{
Ana F. Branco ${ }^{1,2}$, Ana C. Moreira ${ }^{1,2}$, Teresa Cunha-Oliveira ${ }^{1}$, Renata Couto ${ }^{1,2}$, Vilma A. Sardão ${ }^{1}$, \\ Albert A. Rizvanov ${ }^{3}$, András Palotás ${ }^{3,4, *}$ and Paulo J. Oliveira, ${ }^{1, *}$
}

${ }^{I}$ Center for Neuroscience and Cell Biology, University of Coimbra, Portugal; ${ }^{2}$ Department of Life Sciences, University of Coimbra, Portugal; ${ }^{3}$ Kazan Federal University, Russia; ${ }^{4}$ Asklepios-Med (private medical practice and research center), Szeged, Hungary

\begin{abstract}
Neuro-hormonal regulation of cardiac function via cathecol-amines results in increased heart rate and contractility. A persistent adrenergic tone, however, is an insult to the heart, affecting its regular homeostasis, altering morphology and gene expression patterns, as well as inducing apoptosis of cardio-myocytes. At the same time as being the main oxygen consumers, mitochondria are also key to the energy production required for the heart to maintain its vital functions and to integrate a series of signaling pathways that define the life and death of the cell. As $\beta$-adrenergic receptors ( $\beta$-AR) orchestrate multiple biochemical events that can either trigger or inhibit cell death, mitochondria can act as a referee in the entire process. In fact, $\beta$-AR subtypes $\beta_{1}$ and $\beta_{2}$ activate various down-stream pathways which differently modulate intracellular calcium levels and production of mitochondrial reactive oxygen species (ROS). The delicate balance between an adaptive (cardio-protective) response resulting in increased contractility and activation of survival pathways, $v s$. cell death caused by calcium and ROS-induced mitochondrial disruption, along with evidence of their clinical and potential therapeutic translations, are reviewed in this communication.
\end{abstract}

Keywords: Apoptosis, $\beta$-adrenergic receptors, calcium, cardio-myocyte, mitochondria, oxidative stress.

\section{EXCESSIVE $\beta$-ADRENERGIC DRIVE AND CAR- DIAC PATHOLOGY}

Heart failure represents one of the fastest-growing diseases, affecting $8 / 1000$ men at the age group of 50-59 years, and up to 66/1000 men between 80-89 years [1]. It is caused by events that compromise heart function, such as cardiac damage or overload. One example is $\beta$-adrenergic overstimulation following stress-induced release of epinephrine or norepinephrine (NE) to the bloodstream, that may contribute to the increase of fatty acids in the blood, which can then be deposited in arteries, contributing to the development of atherosclerosis $[2,3]$. Since the hardening of blood vessels reduces both the wall diameter and the flow rate, an adaptive response through increased sympathetic nervous system (SNS) activity can initially contribute to increase ventricular contractility in order to sustain ejection performance. However, over time, the neuro-hormonal stimulation of heart rate initiates a process of dynamic and morphological alterations $[4,5]$. When persistent, increased sympathetic nerve activity in the myocardium and accumulation of catecholamines may mechanistically explain pathogenesis of heart disease [6]. Often, the left ventricle develops hypertrophy associated

\footnotetext{
*Address correspondence to these authors at the Asklepios-Med, H-6722 Szeged, Kossuth Lajos sgt. 23, Hungary; Tel: +(36)(30)255-6225;

E-mail: palotas@asklepios-med.eu and Center for Neuroscience and Cell Biology, University of Coimbra, Biotech Building, Lot 8A, Biocant Park, P3060-197 Cantanhede, Portugal;

Tel: +(351)(231)249-195; Fax: +(351)(231)249-179;

E-mail: pauloliv@cnc.uc.pt
}

with a complex set of alterations in the expression of structural and signaling proteins. This may lead to lack of oxygen and nutrients in specific areas of the heart muscle, resulting in the development of irreversible lesions. Commonly, catecholamine over-signaling downstream from $\beta$-adrenergic receptor $(\beta-\mathrm{AR})$ stimulation can lead to cardiomyocyte death through the stimulation of stress responses which involve the activation of apoptotic pathways. Evidences concerning the mechanisms by which cardiac myocytes undergo apoptotic cell death show that mechanical conditions and elevated release of neuro-hormonal factors are strong contributors (Fig. 1) [7].

\section{2. $\beta$-ADRENERGIC OVER-STIMULATION AND CARDIAC CELL DEATH}

Cytotoxic effects of catecholamines on cardiomyocytes are mediated by their interaction with $\alpha$ - and $\beta$-AR. Adrenergic receptors belong to a family of $\mathrm{G}$ protein-coupled receptors (GPCRs) with seven-transmembrane domains, which play an important role on cellular signal transduction by specific agonists. Excess of circulating catecholamines are involved in many cardiac diseases by promoting cellular remodeling, especially when compensatory mechanisms are needed [8].

\subsection{Two Receptors, Two Fates?}

$\beta$-adrenergic receptors link the cardiovascular system with the SNS and can modulate cardioprotection/cardiotoxicity through a crosstalk with multiple signaling pathways. 


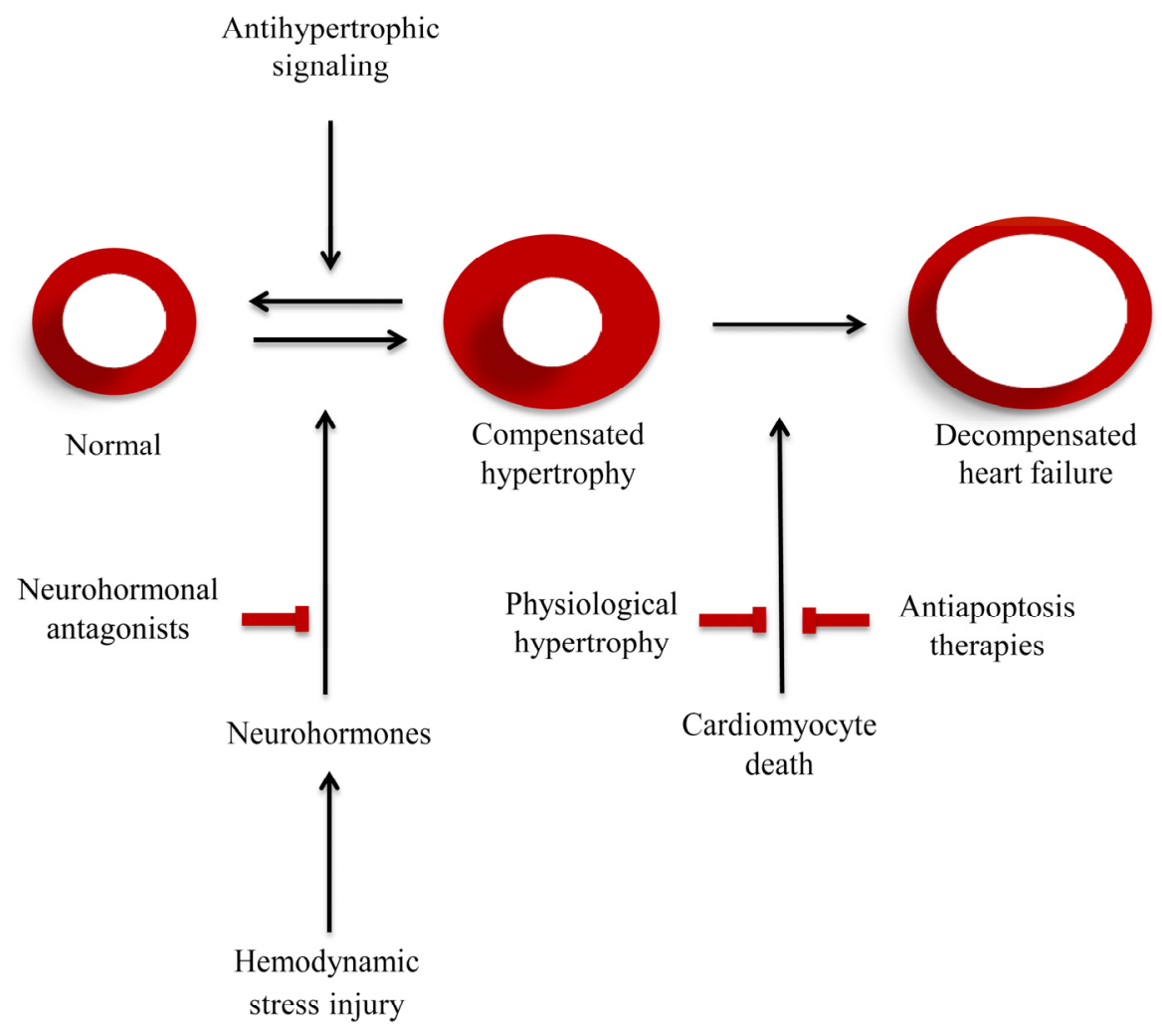

Fig. (1). Representative scheme of morphologic alterations induced by a stressor stimulus in the heart. Terminally differentiated cardiomyocytes adapt to increased work or hemodynamic stressors through an increase in heart rate. To compensate for new cardiac output demand, neurohormonal and cellular signaling cascades are activated, resulting in ventricular remodeling, including increased myocardial mass and ventricular walls thickness. Ultimately, myocardial hypertrophy leads to a progressive loss of cardiomyocytes, which has a causal role in the transition to end-stage disease (Figure adapted from [7, 97]).

Three different $\beta$-ARs subtypes are present in human cardiomyocytes, with the magnitude of expression following a specific order: $\beta_{1}-\mathrm{AR}>\beta_{2}$-AR $>\beta_{3}$-AR [9]. Although being highly homologous, $\beta_{1-}$ and $\beta_{2}-\mathrm{AR}$ receptors clearly play different roles in cardiac physiology and pathology. In fact, chronic stimulation of the two types of receptors has opposing effects on myocyte fate. However, the mechanistic links for their different downstream effects on cardiomyocyte apoptosis are still largely unknown. This agrees with the fact that hundreds of GPCRs use a fairly small pool of second messengers and still remain functionally different [10]. These receptors can be physically coupled to stimulatory (Gs) or inhibitory (Gi) heterotrimeric $G$ proteins (Fig. 2) [11]. Upon ligand binding, a conformational change induced by the exchange of guanosine diphosphate (GDP) for guanosine triphosphate (GTP) in the G protein moiety occurs, leading to protein activation. Both $\beta_{1}$ - and $\beta_{2}-\mathrm{AR}$ are coupled via $G$ proteins to the effector enzyme adenylyl cyclase (AC), which converts the substrate Mg-ATP into the second messenger cyclic adenosine monophosphate (cAMP). Then, cAMP-dependent protein kinase A (PKA) mediates the phosphorylation of proteins involved in cardiomyocyte calcium $\left(\mathrm{Ca}^{2+}\right)$ handling [12-14], contributing to the regulation of multiple signaling pathways.

Despite its role as a pro-death receptor [15], stimulation of $\beta_{2}$-AR can also activate survival pathways via coupling to Gi proteins [15] that involves activation of phosphatidylinositol 3-kinase (PI3K) and Akt [16], and is able to inhibit the pro-apoptotic signaling axis AC-cAMP-PKA [17-19]. However, it still remains to be understood how cardiac myocytes activate the $\beta_{2}$-AR-based pathway and have distinctly variable biological consequences on cell death/survival. Clearly, downstream partners determine the cellular fate.

Transgenic rodents over-expressing cardiac $\beta_{1}$-AR-Gs presented increased cardiomyopathic phenotype, as well as increased basal rates of cardiomyocyte apoptosis [20]. Moreover, the pro-apoptotic role of $\beta_{1}$-receptor activation is also dependent on oxidative stress, while other mechanisms imply PKA-independent activation of $\mathrm{Ca}^{2+} /$ calmodulindependent protein kinase (CaMK) (Fig. 2) [21]. However, it must be stressed that downstream effects of $\beta$-adrenergic signaling cannot be completely beneficial or deleterious, due to the complex mechanisms of molecular interactions. The tissue content in $\beta$-ARs is not constant and modulation of receptor expression levels is one of the dynamic mechanisms by which transmembrane $\beta$-AR signaling is achieved. The amount of $\beta$-ARs present in a tissue is modulated by a variety of drugs, hormones, physiological and pharmacological conditions [22]. Interestingly, $\beta_{1}$-AR antagonists, in combination with $\beta_{2}$-AR agonists, improved cardiac activity and inhibited deleterious cardiac remodeling, when compared with the single use of a $\beta_{1}$-AR antagonist in a heart failure rat model [23]. Also, downregulation of pro-apoptotic protein Bax and an increase in the anti-apoptotic protein Bcl-2 may contribute to the beneficial effects of the joint therapy in preventing cardiomyocyte apoptosis in these animals [24]. 


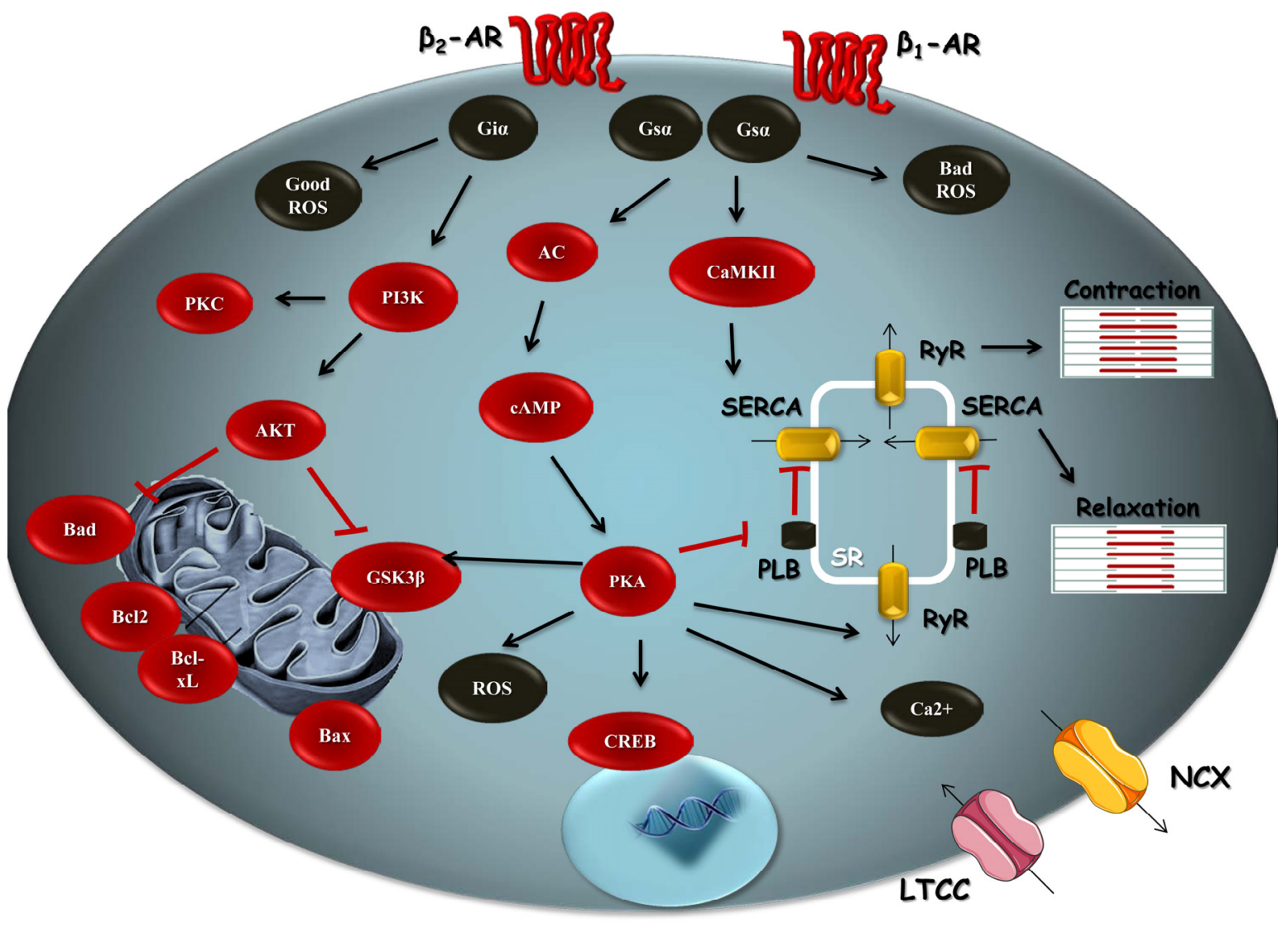

Fig. (2). Integrative schematics of signaling pathways triggered by $\boldsymbol{\beta}$-adrenergic receptors. $\beta_{1}$ and $\beta_{2}$-adrenergic receptors modulate cellular behavior via several distinct signaling pathways. In this highly regulated system, maintenance of physiologic calcium levels and preventing the up-regulation of pro-apoptotic elements is critical for cell death control. $\beta_{1}$-AR is reported as pro-apoptotic, being coupled to a stimulatory $\mathrm{G}$ protein which activates PKA via adenylate cyclase and cAMP. The activation of PKA initiates the influx of calcium by activating the L-type calcium channels (LTCC) in cell membranes. The increase in intracellular $\mathrm{Ca}^{2+}$ together with the concomitant stimulation of RyR by PKA, leads to $\mathrm{Ca}^{2+}$ release from the sarcoplasmic reticulum which stimulates cardiac contraction. PKA is also involved in the activation of SERCA which contributes to muscle relaxation by promoting calcium re-uptake from the cytosol. $\beta_{2}$-adrenergic receptor signals via both stimulatory and inhibitory $\mathrm{G}$ proteins and is associated with anti-apoptotic pathways, such as PI3K/Akt, contributing to inhibit apoptosis.

In fact, our group has shown that a decrease in the Bcl-2/Bax ratio is associated with increased $\beta$-AR-induced cardiomyoblast death [25]. The effects of $\beta$-AR stimulation may also depend on the stage of cardiac cell differentiation. By using $\mathrm{H} 9 \mathrm{c} 2$ cardiomyoblasts as an experimental model, our group demonstrated that the stimulation of $\beta$-AR by the nonselective agonist isoproterenol (ISO) leads to different cellular responses depending on the differentiation state of cells. Undifferentiated cells, unlike differentiated ones, developed higher protective stress responses to injury promoted by ISO [25]. When incubated with ISO, differentiated H9c2 muscle cells showed increased cytosolic $\mathrm{Ca}^{2+}$, cAMP content and oxidative stress, as well as mitochondrial depolarization, increased levels of superoxide anion $\left(\mathrm{O}_{2}{ }^{-}\right)$, loss of subunits from the mitochondrial respiratory chain, decreased $\mathrm{Bcl}-\mathrm{xL}$ content, increased p53 and phosphorylated-p66Shc, as well as activated caspase-3. On the other hand, undifferentiated $\mathrm{H} 9 \mathrm{c} 2$ cells incubated with ISO showed increased Bcl-xL protein and increased mitochondrial superoxide dismutase (SOD) expression, which may act as protective mechanisms. These results suggested that the differentiation of cardiomyoblasts is associated with differential regulation of stress responses, which impact the toxicity of several agents, namely those acting through $\beta$-AR and resulting in mitochondrial disruption in differentiated cells only [25]. These results also suggest that multiple cell signaling pathways, including those linked to $\beta$-AR, modulate cell fate by up or down-regulating mitochondrial processes, including oxidative stress and calcium signaling.

\subsection{From Receptor Activation to Cell Fate: The Role of Calcium and ROS Signaling}

Reactive oxygen species (ROS) are formed as a natural byproduct of oxygen metabolism, and regulate various biological responses such as cell proliferation, tumor progression, hypertrophy, and apoptosis, among others. Since the majority of oxygen consumption for cellular metabolism occurs through oxidative phosphorylation, mitochondria are described as important sources of ROS in the cell [26], predominately under pathological conditions [27].

Studies in animal models showed that the addition of exogenous oxidants scavengers provided strong anti-apoptotic action in cardiac cells, demonstrating that oxidative stress may be, at least partially, involved in myocyte degeneration [28]. 
At low levels, ROS generation has an important role in signaling functions in cardiac cells by mediating cell proliferation, differentiation and survival pathways [29]. During cardiomyogenesis, mitochondrial ROS formation has an important role in establishing the metabolic mechanisms that allow undifferentiated myoblasts drive to a cardiac-specific energetic requirement [30-32]. Our recent study demonstrated that differentiated $\mathrm{H} 9 \mathrm{c} 2$ cells generate higher content of mitochondrial $\mathrm{O}_{2}{ }^{-}$[30], supporting the hypothesis that redox signaling alterations are required for myoblasts differentiation [33]. In the heart, the excitation-contraction coupling (ECC) is a physiological process essential for cardiomyocyte function (contraction and relaxation), and involves redox signaling [34]. Modulation of ECC is one of the adaptive processes in which low-level production of ROS may be involved [35].

Mitochondrial sources of $\mathrm{O}_{2}{ }^{-}$include the respiratory chain, and the enzymes dehydrolipoamide dehydrogenase (DLD), monoamine oxidase (MAO), aconitase, and nicotinamide adenine dinucleotide phosphate (NADPH) oxidases (NOX) $[36,37]$. In the respiratory chain, complexes I and III have been described as important sources of $\mathrm{O}_{2}{ }^{--}$[38]. At both complexes, superoxide anion is formed on Fe-S clusters, upstream from ubiquinone reduction. The generation of this radical is increased by the presence of rotenone and antimycin A, complex I and III inhibitors, respectively, thus demonstrating the role of these two complexes for mitochondrial ROS generation [39].

Particularly relevant to $\beta$-AR-induced overstimulation and intracellular effects are two mitochondrial ROS generation enzymatic generators: MAO and NOX. Two isoforms of MAO exist bound to the outer mitochondrial membrane (MAO-A and MAO-B). These oxidases are also flavoproteins and catalyze the oxidation of amines to molecular oxygen, leading to the formation of aldehydes and hydrogen peroxide $\left(\mathrm{H}_{2} \mathrm{O}_{2}\right)$ [40]. These enzymes are involved in catecholamine catabolism, particularly the MAO-A isoform, and were described to be important ROS sources, as byproducts of the catabolism of neurotransmitters such as norepinephrine and dopamine, leading to $\mathrm{H}_{2} \mathrm{O}_{2}$ formation [35]. A decrease in oxidative stress, inhibition of contractile dysfunction, inhibition of matrix metalloproteinase and caspase- 3 activation were observed in mice with pressure overload-induced heart failure when treated with the MAO-A inhibitor, clorgyline, or in a dominant-negative MAO-A model $[35,41]$.

Increased NOX-induced ROS production and progressive ventricular dysfunction were reported to occur in $\beta_{2}$-AR overexpressing transgenic mice, leading to activated p38 mitogen-activated protein kinase (p38 MAPK), and significantly contributing to cardiac inflammation, remodeling and failure [42]. The NOX family enzymes catalyze formation of ROS and protons [34] derived from electron transfer from NADPH to NOX flavin domains. These enzymes are key regulators of redox signaling in several organisms, including during cell proliferation and differentiation. In particular, heart-expressing isoforms NOX2 and NOX4 contribute to $\mathrm{O}_{2}{ }^{-}$and $\mathrm{H}_{2} \mathrm{O}_{2}$ production, respectively [34, 43, 44]. Interestingly, NOX4 was shown to be located in intracellular space of cardiomyocytes in various sites, including the endoplasmic reticulum, nucleus and mitochondria [34] and to be a major source of mitochondrial oxidative stress in cardiomyocytes [45]. Several molecular targets can be regulated by free radicals in cardiomyocytes, such as protein phosphatases, kinases, ion transporters, transcription factors and receptors [34].

Besides ROS, $\mathrm{Ca}^{2+}$ is also important in the regulation of several intracellular pathways in cardiac cells, namely in the control of cardiac beating and other signaling pathways. Calmodulin-dependent kinase II (CaMKII) activity is stimulated during pro-oxidant conditions, promoting the phosphorylation of cardiac $\mathrm{Ca}^{2+}$-handling proteins, leading to modulation ECC, apoptosis and gene transcription [34]. After oxidation and formation of disulfide bonds, PKA acquires higher affinity for binding to A-kinase anchoring proteins (AKAPs) [34, 46], allowing the localization of PKA in particulate membranes and cellular organelles [47]. Mitochondria have a specific subset of AKAPs, including AKAP121 [48]. Some studies demonstrate that the complex AKAP121PKA inhibits the mitochondrial apoptotic pathway by phosphorylation of the pro-apoptotic protein $\mathrm{BAD}$, blocking its association with Bcl-2 [49]. Therefore, upon $\beta$-AR stimulation, the cAMP-PKA pathway can be activated leading to mitochondrial protection. More recently, the existence of a cAMP signaling microdomain in the outer mitochondrial membrane (OMM) with higher PKA activity pointed out the mitochondrial localization of this holoenzyme [50]. These findings, although controversial, suggest that cAMPtriggered activity in mitochondria is not only due to PKA interaction with specific AKAPs, but may also be due to this compartmentalization. Moreover, PKA mediates the phosphorylation of several substrates, contributing to the regulation of several cell signaling pathways. For instance, $\beta$-ARregulated $\mathrm{Ca}^{2+}$ handling in cardiac cells is regulated by mitochondrial ROS production, since these modulate ryanodine receptors (RyRs) through phosphorylation and oxidation, leading to increased $\mathrm{Ca}^{2+}$ leakage and to inhibition of sarcoplasmic reticulum (SR) $\mathrm{Ca}^{2+}$ uptake $[12,51]$. Protein kinase A can phosphorylate phospholamban, a protein that regulates cardiac SR Ca-ATPase (SERCA), which is indirectly redox regulated. Moreover, it can also be directly regulated through thiol oxidation [34].

Under normal conditions, mitochondrial metabolism can be stimulated by $\mathrm{Ca}^{2+}$, providing an increase in reduced nicotinamide adenine dinucleotide (NADH) and adenosine triphosphate (ATP) production [52]. On the other hand, $\mathrm{Ca}^{2+}$ overload can lead to mitochondrial dysfunction and increased $\mathrm{O}_{2}{ }^{-}$production, leading to mitochondrial permeability transition pore (MPTP) induction and triggering of cell death [53]. Several studies indicate an association between cytosolic $\mathrm{Ca}^{2+}$ and ROS generation, not only at the mitochondrial level but also in other organelles. In addition, ROS can stimulate the rise in intracellular $\mathrm{Ca}^{2+}$ concentration [54].

In mitochondria, excessive $\mathrm{Ca}^{2+}$ uptake is one of the mechanisms that may lead to ROS generation, resulting from high levels of intracellular $\mathrm{Ca}^{2+}[54,55]$. Nevertheless, heart mitochondria have the capacity to store large amounts of $\mathrm{Ca}^{2+}$ without triggering the MPTP [56], but when the heart tissue suffers an insult, such as during cardiac reperfusion, oxidative stress largely increases, and lower mitochondrial $\mathrm{Ca}^{2+}$ concentrations can lead to disrupted function [57]. 
The interaction between $\mathrm{Ca}^{2+}$ and oxidative stress regulates other stress pathways involved in cell death, such as the p66Shc pathway [30]. p66Shc is known to regulate oxidative stress responses and apoptosis [58]. The phosphorylation of p66Shc on serine 36 by protein kinase $C \beta$ increases during cellular stress, leading to an amplification of mitochondrial oxidative stress and apoptotic signaling [59]. In a previous study, we demonstrated that the $\beta$-AR agonist ISO increases the ratio between Ser36-phosphorylated p66Shc and the total p66Shc content in differentiated cardiac cells [30], suggesting a pro-apoptotic/pro-oxidant effect.

The dual effects of mitochondrial ROS on $\beta$-AR-induced modulation of cardiomyocyte function are well described. As mentioned above, mitochondria are an important source of intracellular ROS and complexes I and III have been described as potential sources of ROS, including $\mathrm{O}_{2}^{--^{-}}$[60]. Therefore, one hypothesis is that there may be an association between $\beta$-AR pathways at the sarcolemma and ROS generation at the mitochondrial level. In this regard, if $\mathrm{Ca}^{2+}$ influx resulting from persistently activated $\beta-\mathrm{AR}$, or if $\mathrm{Ca}^{2+}$ removal systems are compromised, as during chronic $\beta$-AR stimulation, $\mathrm{Ca}^{2+}$ overload can occur $[61,62]$ leading to excessive mitochondrial $\mathrm{Ca}^{2+}$ uptake [63]. When $\mathrm{Ca}^{2+}$ exceeds a certain threshold, the mitochondrial buffering capacity is overloaded and a substantial mitochondrial $\mathrm{Ca}^{2+}$ accumulation occurs. In certain tissues, such as in muscle, calcium overaccumulation, accompanied by oxidative stress, facilitates MPTP opening and forces mitochondrial electron transfer to accelerate, contributing to higher ROS generation by the respiratory chain [64].

Despite this, moderate $\beta$-AR-induced ROS release from the respiratory chain regulates $\mathrm{Ca}^{2+}$ transient amplitude, contraction and L-type $\mathrm{Ca}^{2+}$ current densities, while persistent $\beta$ adrenergic stress compromises cardiac viability, most likely by persistently inducing mitochondrial oxidative stress [65]. In fact, long-term $(24 \mathrm{~h}) \beta$-AR stimulation induced mitochondrial membrane depolarization and apoptosis in adult rat cardiomyocytes [66, 67]. Induction of cell death was inhibited by a SOD/catalase mimetic and by the overexpression of catalase, which indicated that the apoptotic signaling induced by $\beta$-ER stimulation involved increased ROS production [66].

Activation of PKA can also induce a fast and reversible increase in mitochondrial ROS generation in rat cardiomyocytes [68]. In a similar study using mouse ventricular cardiomyocytes, the $\beta$-AR agonist ISO induced mitochondrial ROS production via cAMP-PKA and stimulated cytoplasmic $\mathrm{Ca}^{2+}$ transients, which were blunted by pre-incubation with antioxidants [65]. In addition, mice hearts perfused with ISO showed increased mitochondrial ROS production, which was independent of mitochondrial $\mathrm{Ca}^{2+}$ accumulation or membrane depolarization [65], but resulted instead from cAMPPKA signaling pathway stimulation. Moreover, increased mitochondrial ROS production plays a critical role in the $\beta$ adrenergic inotropic effect since ISO-induced $\mathrm{Ca}^{2+}$ transients are diminished in the presence of the antioxidant $\mathrm{N}$-acetylcysteine (NAC), as well as by the mitochondria-targeted antioxidant SS3 [65]. These approaches do not exclude that other pathways, linking $\beta$-AR signaling to specific proteins in mitochondria (such as MAO) may be occurring.

\section{THE $\beta$-ADRENERGIC SYSTEM AND DOWN- STREAM MITOCHONDRIAL SIGNALING AS A THERAPEUTIC TARGET}

\subsection{A Protective Role for NOS?}

Besides ROS, reactive nitrogen species (RNS) also contribute to oxidative stress. Nitric oxide synthase (NOS) is a cytochrome $\mathrm{P} 450$ reductase-like enzyme that catalyzes flavin-mediated electron transfer from NADPH to a prothestic heme group. This reaction leads to the generation of nitric oxide (NO), which is a relatively stable radical, with an halflife of up to $10 \mathrm{~s}$. The simultaneous production of mitochondrial $\mathrm{NO}$ and $\mathrm{O}_{2}{ }^{--}$results in the production of peroxynitrite, a very damaging agent [69]. However, NO also plays an important role in the regulation of cardiovascular function, including the regulation of protein trafficking in the cardiovascular system [70]. Besides activating the cGMP-dependent pathway, NO can also regulate cell function through protein S-nitrosylation, a reversible, redox dependent, posttranslational protein modification that involves the binding of $\mathrm{NO}$ to a protein sulfhydryl group. S-nitrosylation of proteins seems to play an important role in cardioprotection, leading to changes in protein structure and function, and also preventing further irreversible oxidative/nitrosative modification of the modified thiol groups [71, 72]. Protein Snitrosylation also has an important role of in modulating mitochondrial respiration. Mitochondrial S-nitrosylated proteins (including complex I) are associated with mainly protective effects, as in inflammatory and ischemia/reperfusion syndromes, but also in some pathological effects, as in neurodegenerative diseases [73]. However, it remains to be known if local mitochondrial NO effects are important in the context of cell protection.

\subsection{Mitochondria as a Drug Target}

The data described above imply that a stress response to $\beta$-AR stimulation often involves an increased generation of ROS by mitochondria, which may initially serve as an adaptive feature, aiming at improving the antioxidant network and contraction. On the other hand, continued mitochondrial ROS production can result in organelle degeneration and induction of cell death. However, there are still open questions, especially regarding the mechanisms on how mitochondria are stimulated to generate more ROS. Nevertheless, the way in which cardiomyocyte oxidative stress is managed following $\beta$-adrenergic stimulation depends on the type of receptor involved. For example, $\beta_{2}$-AR activation was shown to afford cardioprotective effects during oxidative stress induced by doxorubicin (DOX) in cardiomyocytes. Although the cardiotoxicity exerted by this anti-neoplastic agent is mediated in part through $\mathrm{Ca}^{2+}$-dependent opening of the MPTP [74], the signals linking $\beta_{2}$-AR signaling to the prevention of DOX toxicity through this pathway are unclear. Although DOX administration to wild type mice resulted in no acute mortality, $85 \%$ of $\beta_{2}-\mathrm{AR}^{-/}$mice died within $30 \mathrm{~min}$ after DOX administration [75]. $\beta_{2}$-AR activation of prosurvival kinases appears to be essential for mitochondrial preservation. Likewise, knock-down of those receptors negatively regulates pro-survival kinases, increases intracellular $\mathrm{Ca}^{2+}$ levels, potentiating mitochondrial dysfunction by induction of oxidative stress and MPTP opening, which represent 
a critical step on cardiotoxic events [75]. Another study using ventricular myocytes isolated from wild type (C57BL/6) and NOS1 knockout $\mathrm{NOS}^{-/-}$mice, demonstrated that scavenging $\mathrm{O}_{2}{ }^{-}$and increasing $\mathrm{NO}$ levels to an adequate $\mathrm{NO} / \mathrm{O}_{2}{ }^{-}$ balance improved myocyte $\mathrm{Ca}^{2+}$ transients in response to $\beta$ adrenergic stimulation [76]. In fact, moderate ROS production enhances $\mathrm{Ca}^{2+}$ fluxes in cardiomyocytes, resulting in more vigorous contraction. However, elevated $\mathrm{O}_{2}{ }^{-}$production affects a variety of proteins involved in ECC, leading to contractile dysfunction [77].

It is known that $\beta$-AR blockers improve cardiac contractility and reduce mortality in patients with heart failure [78]. However, it is still unclear how blocking a pathway that increases contractility in normal hearts can improve the function of a failing heart. Although poorly understood, the competition for NE receptors may attenuate cardiomyocyte overstimulation, with $\mathrm{Ca}^{2+}$ playing a pivotal role [79]. As described above, $\beta$-AR stimulation activates both AC-cAMPPKA and CaMKII pathways [80]. Similarly to PKA signaling, CaMKII is upregulated in failing hearts [81].

By using a knockout mice for type 5 AC (AC5KO), a major cardiac isoform, a long-term ISO treatment (7 to 14 days) did not result in further increase of left ventricular ejection fraction (LVEF) as observed in wild type animals. Instead, ISO treatment in AC5KO animals resulted in a greater degree of AC signaling downregulation, an improvement on myocyte viability and increased $\mathrm{Bcl}-2$ protein expression and Akt/GSK signaling, potentially elucidating a novel approach to the therapy of heart failure and a protective mechanism of mitochondrial integrity [82]. In this regard, several studies are focused on cellular checkpoints that provide 'rescue' opportunities for cardiomyocytes. The control of pro-apoptotic regulatory mechanisms protects cells from complete execution of the apoptotic program. Studies in experimental animals have shown that Bcl-2 affords strong anti-apoptotic effects and overexpression of this protein provided cardioprotection [83]. Similar results were also obtained in studies using exogenous oxidants scavengers [28].

The development of therapies aiming at increasing mitochondrial biogenesis can be useful for cell repair and/or regeneration. In fact, by using adult feline cardiomyocytes exposed to the $\beta$-AR agonist formoterol, increased mitochondrial biogenesis was observed [84]. At least in adipocytes, nebivolol, a third-generation $\beta$-AR blocker stimulates mitochondrial biogenesis, increasing mitochondrial DNA copy number, protein levels and the expression of transcription factors involved in mitochondrial biogenesis, such as PPAR- $\gamma$ coactivator- $1 \alpha$ (PGC-1 $\alpha$ ), Sirtuin 3 (Sirt3), mitochondrial transcription factor A (Tfam) and nuclear related factor 1 (Nrf1) [85], supporting the use and development of $\beta_{2}$-AR ligands for therapeutic mitochondrial biogenesis. Also, the $\beta$-AR blocker carvedilol demonstrated cardiac protection in a variety of settings [86]. Although the hemodynamic effects result mostly from non-selective $\beta$-AR blockage and selective alpha-receptor blockage, carvedilol also prevents cardiac mitochondrial deterioration resulting from oxidative stress [87-92]. It is thought that antioxidant protection afforded by carvedilol may be originated from mechanisms ranging from iron chelation [93] to a sub-toxic genera- tion of ROS which acts to precondition the heart tissue against deleterious insults [94]. It appears that the antiapoptotic effects of carvedilol can have multiple effects besides direct anti-oxidant protection. Novel mechanisms include up-regulation of anti-apoptotic miRNA [95] and regulation of phosphatidylinositol 3-kinase and mitogen-activated protein-kinase kinase pathways [96]. How blockage of $\beta$-AR triggers these effects or whether those are completely independent events still remains to be determined.

\section{CONCLUSION}

We hereby provide evidence that mitochondria play a key role in $\beta$-AR downstream signaling namely regarding the regulation of $\mathrm{Ca}^{2+}$ fluxes, ROS production and integration of pro- and anti-apoptotic signals. Nevertheless, it is still far from being understood how the different pathways crosslink/divide downstream from the two receptors to generate distinct effects on mitochondria and cell viability. Therapeutics aimed at preventing mitochondrial degeneration during $\beta$-AR over-stimulation in various cardiac conditions may be a useful strategy, namely using antioxidants targeted to mitochondria, although still little work has been done in this regard.
ABBREVIATIONS
$\mathrm{AC}=$ Adenylate cyclase
$\mathrm{AC} 5 \mathrm{KO}=$ Knockout mice for type $5 \mathrm{AC}$
AKAPs $=$ A-kinase anchoring proteins
ATP $=$ Adenosine triphosphate
$\mathrm{Bad}=\mathrm{Bcl}-2$-associated death promoter
Bax $=$ Bcl-2-associated $\mathrm{X}$ protein
Bcl-2 = B-cell lymphoma 2
Bcl-xL = B-cell lymphoma-extra-large
$\mathrm{Ca}^{2+}=$ Calcium
CaMK $=\mathrm{Ca}^{2+} /$ calmodulin-dependent protein kinase
CaMKII $=\mathrm{Ca}^{2+} /$ calmodulin-dependent protein kinase
cAMP = Cyclic adenosine monophosphate
cGMP = Cyclic guanosine monophosphate
CREB $=$ cAMP response element-binding protein
DLD $=$ Dehydrolipoamide dehydrogenase
DOX $=$ Doxorubicin
ECC $=$ Excitation-contraction coupling
GDP = Guanosine diphosphate
$\mathrm{Gi}=$ Guanine nucleotide-binding protein inhibitory subunit
GPCRs $=$ G protein-coupled receptors
Gs $=$ Guanine nucleotide-binding protein stimula- tory subunit
GSK = Glycogen synthase kinase $3 \beta$
GTP $=$ Guanosine triphosphate 


$$
\begin{aligned}
& \mathrm{H}_{2} \mathrm{O}_{2}=\text { Hydrogen peroxide } \\
& \text { ISO }=\text { Isoproterenol } \\
& \text { LEVF }=\text { Left ventricular ejection fraction } \\
& \text { LTCC }=\text { L-type calcium channel } \\
& \text { MAO }=\text { Monoamine oxidase } \\
& \text { MPTP }=\text { Mitochondrial permeability transition pore } \\
& \mathrm{NAC}=\mathrm{N} \text {-acetyl-cysteine } \\
& \mathrm{NADH}=\text { Nicotinamide adenine dinucleotide } \\
& \mathrm{NADPH}=\text { Nicotinamide adenine dinucleotide phosphate } \\
& \text { NCX }=\text { Sodium-calcium exchanger } \\
& \mathrm{NE} \quad=\text { Norepinephrine } \\
& \mathrm{NO} \quad=\text { Nitric oxide } \\
& \text { NOS }=\text { Nitric oxide synthase } \\
& \text { NOX }=\text { NADPH oxidases } \\
& \text { Nrf-1 = Nuclear-related factor } 1 \\
& \mathrm{O}_{2}{ }^{--}=\text {Superoxide anion } \\
& \mathrm{OMM}=\text { Outer mitochondrial membrane } \\
& \mathrm{p} 38=\mathrm{p} 38 \text { mitogen-activated protein kinases } \\
& \mathrm{PGC} 1 \alpha=\text { Peroxisome proliferator-activated receptor- } \gamma \\
& \text { co-activator } 1 \alpha \\
& \text { PI3-K = Phosphoinositide 3-kinase } \\
& \text { PKA }=\text { Protein kinase } \mathrm{A} \\
& \mathrm{PKC}=\text { Protein kinase } \mathrm{C} \\
& \text { PLB = Phospho-lamban } \\
& \text { RNS }=\text { Reactive nitrogen species } \\
& \text { ROS }=\text { Reactive oxygen species } \\
& \text { RyRs }=\text { Ryanodine receptors } \\
& \text { SERCA }=\text { SR Ca-ATPase } \\
& \text { Sirt3 = Sirtuin } 3 \\
& \text { SNS }=\text { Sympathetic nervous system } \\
& \text { SOD2 }=\text { Superoxide dismutase } \\
& \mathrm{SR}=\text { Sarcoplasmic reticulum } \\
& \text { Tfam }=\text { Mitochondrial transcription factor } \mathrm{A} \\
& \beta \text {-AR }=\beta \text {-adrenergic receptor }
\end{aligned}
$$

\section{CONFLICT OF INTEREST}

The authors confirm that this article content has no conflict of interest.

\section{ACKNOWLEDGEMENTS}

The research in the authors' laboratory is supported by Foundation for Science and Technology, Portugal, grants PTDC/SAU-TOX/117912/2010, PEst-C/SAU/LA0001/ 2013-2014 and co-funded by FEDER/Compete and National Budget (to PJO), CENTRO-07-ST24-FEDER-002008 (to TCO and VAS), as well as personal fellowships
(SFRH/BD/33892/2009 to A.C.M. and SFRH/BD/41384/ 2007 to A.F.B.). AAR and AP were supported by Russian Federation Program of Competitive Growth of Kazan Federal University and subsidy allocated to Kazan Federal University for the state assignment in the sphere of scientific activities.

\section{REFERENCES}

[1] Ho KK, Pinsky JL, Kannel WB, Levy D. The epidemiology of heart failure: the Framingham Study. J Am Coll Cardiol 1993; 22(4 Suppl A): 6A-13A.

[2] Bachman ES, Dhillon H, Zhang CY, et al. $\beta \mathrm{AR}$ signaling required for diet-induced thermogenesis and obesity resistance. Science 2002; 297(5582): 843-5.

[3] Barrett AM. The mobilization of free fatty acids in response to isoprenaline in the rat. Br J Pharmacol Chemother 1965; 25(2): 545-56.

[4] Briest W, Holzl A, Rassler B, et al. Cardiac remodeling after long term norepinephrine treatment in rats. Cardiovasc Res 2001; 52(2): 265-73.

[5] Ren R, Oakley RH, Cruz-Topete D, Cidlowski JA. Dual role for glucocorticoids in cardiomyocyte hypertrophy and apoptosis. Endocrinology 2012; 153(11): 5346-60.

[6] Colucci WS. The effects of norepinephrine on myocardial biology: implications for the therapy of heart failure. Clin Cardiol 1998; 21(12 Suppl 1): I20-4.

[7] Diwan A, Dorn GW, 2nd. Decompensation of cardiac hypertrophy: cellular mechanisms and novel therapeutic targets. Physiology (Bethesda) 2007; 22: 56-64

[8] Machackova J, Sanganalmath SK, Barta J, Dhalla KS, Dhalla NS Amelioration of cardiac remodeling in congestive heart failure by $\beta$-adrenoceptor blockade is associated with depression in sympathetic activity. Cardiovasc Toxicol 2010; 10(1): 9-16.

[9] Lohse MJ, Engelhardt S, Eschenhagen T. What is the role of $\beta$ adrenergic signaling in heart failure? Circ Res 2003; 93(10): 896906.

[10] Gupta MK, Neelakantan TV, Sanghamitra M, et al. An assessmen of the role of reactive oxygen species and redox signaling in norepinephrine-induced apoptosis and hypertrophy of $\mathrm{H} 9 \mathrm{c} 2$ cardiac myoblasts. Antioxid Redox Signal 2006; 8(5-6): 1081-93.

[11] Singh K, Xiao L, Remondino A, Sawyer DB, Colucci WS. Adrenergic regulation of cardiac myocyte apoptosis. J Cell Physiol 2001; 189(3): 257-65.

[12] Bovo E, Lipsius SL, Zima AV. Reactive oxygen species contribute to the development of arrhythmogenic $\mathrm{Ca}(2)(+)$ waves during $\beta$ adrenergic receptor stimulation in rabbit cardiomyocytes. J Physiol 2012; 590(Pt 14): 3291-304.

[13] Aschar-Sobbi R, Emmett TL, Kargacin GJ, Kargacin ME. Phospholamban phosphorylation increases the passive calcium leak from cardiac sarcoplasmic reticulum. Pflugers Arch 2012; 464(3): 295-305.

[14] Hui K, Arnot M, Shin HS, Sun HS, Feng ZP. Differential regulation of low and high voltage-activated calcium channels in neonatal rat myocytes following chronic PKA modulation. Channels (Austin) $2011 ; 5(4): 357-66$.

[15] Zhu WZ, Zheng M, Koch WJ, et al. Dual modulation of cell survival and cell death by $\beta_{2}$-adrenergic signaling in adult mouse cardiac myocytes. Proc Natl Acad Sci USA 2001; 98(4): 1607-12.

[16] Amin P, Singh M, Singh K. $\beta$-adrenergic receptor-stimulated cardiac myocyte apoptosis: role of $\beta 1$ integrins. J Signal Transduct 2011;2011: 179057

[17] Zhu W, Zeng X, Zheng M, Xiao RP. The enigma of $\beta 2$-adrenergic receptor Gi signaling in the heart: the good, the bad, and the ugly. Circ Res 2005; 97(6): 507-9.

[18] Ahmet I, Krawczyk M, Heller P, et al. Beneficial effects of chronic pharmacological manipulation of $\beta$-adrenoreceptor subtype signaling in rodent dilated ischemic cardiomyopathy. Circulation 2004; 110(9): 1083-90.

[19] Patterson AJ, Zhu W, Chow A, et al. Protecting the myocardium: a role for the $\beta 2$ adrenergic receptor in the heart. Crit Care Med 2004; 32(4): 1041-8.

[20] Petrashevskaya N, Gaume BR, Mihlbachler KA, Dorn GW, 2nd, Liggett SB. Bitransgenesis with $\beta 2$-adrenergic receptors or 
adenylyl cyclase fails to improve $\beta 1$-adrenergic receptor cardiomyopathy. Clin Transl Sci 2008; 1(3): 221-7.

[21] Zhu WZ, Wang SQ, Chakir K, et al. Linkage of $\beta 1$-adrenergic stimulation to apoptotic heart cell death through protein kinase Aindependent activation of $\mathrm{Ca}^{2+} /$ calmodulin kinase II. J Clin Invest 2003; 111(5): 617-25.

[22] Brodde OE. Molecular pharmacology of $\beta$-adrenoceptors. J Cardiovasc Pharmacol 1986; 8 Suppl 4: S16-20.

[23] Ahmet I, Morrell C, Lakatta EG, Talan MI. Therapeutic efficacy of a combination of a $\beta 1$-adrenoreceptor (AR) blocker and $\beta_{2}$-AR agonist in a rat model of postmyocardial infarction dilated heart failure exceeds that of a $\beta 1-\mathrm{AR}$ blocker plus angiotensin-converting enzyme inhibitor. J Pharmacol Exp Ther 2009; 331(1): 178-85.

[24] Li WM, Gan RT, Wang X, et al. [The effects of combined $\beta 1$ adrenergic receptor antagonist and $\beta 2$ adrenergic receptor agonist therapy on cardiac function and myocardial apoptosis in heart failure rats]. Zhonghua Xin Xue Guan Bing Za Zhi 2007; 35(7): 615-9.

[25] Branco AF, Pereira SL, Moreira AC, et al. Isoproterenol cytotoxicity is dependent on the differentiation state of the cardiomyoblast H9c2 cell line. Cardiovasc Toxicol 2011; 11(3): 191-203.

[26] Suski JM, Lebiedzinska M, Bonora M, et al. Relation between mitochondrial membrane potential and ROS formation. Methods Mol Biol 2012; 810: 183-205.

[27] Brown GC, Borutaite V. There is no evidence that mitochondria are the main source of reactive oxygen species in mammalian cells. Mitochondrion 2012; 12(1): 1-4.

[28] Qin F, Shite J, Liang CS. Antioxidants attenuate myocyte apoptosis and improve cardiac function in CHF: association with changes in MAPK pathways. Am J Physiol Heart Circ Physiol 2003; 285(2): H822-32.

[29] Doenst T, Nguyen TD, Abel ED. Cardiac metabolism in heart failure: implications beyond ATP production. Circ Res 2013; 113(6): 709-24.

[30] Branco AF, Sampaio SF, Wieckowski MR, Sardao VA, Oliveira PJ. Mitochondrial disruption occurs downstream from $\beta$-adrenergic overactivation by isoproterenol in differentiated, but not undifferentiated $\mathrm{H} 9 \mathrm{c} 2$ cardiomyoblasts: differential activation of stress and survival pathways. Int J Biochem Cell Biol 2013; 45(11): 2379-91.

[31] San Martin N, Cervera AM, Cordova C, et al. Mitochondria determine the differentiation potential of cardiac mesoangioblasts. Stem Cells 2011;29(7): 1064-74.

[32] Chung S, Dzeja PP, Faustino RS, et al. Mitochondrial oxidative metabolism is required for the cardiac differentiation of stem cells. Nat Clin Pract Cardiovasc Med 2007; 4 Suppl 1: S60-7.

[33] Schmelter M, Ateghang B, Helmig S, Wartenberg M, Sauer H. Embryonic stem cells utilize reactive oxygen species as transducers of mechanical strain-induced cardiovascular differentiation. FASEB J 2006; 20(8): 1182-4.

[34] Burgoyne JR, Mongue-Din H, Eaton P, Shah AM. Redox signaling in cardiac physiology and pathology. Circ Res. 2012; 111(8): 1091106.

[35] Santos CX, Anilkumar N, Zhang M, Brewer AC, Shah AM. Redox signaling in cardiac myocytes. Free Radic Biol Med. 2011; 50(7): 777-93.

[36] Turrens JF. Mitochondrial formation of reactive oxygen species. J Physiol 2003; 552(Pt 2): 335-44.

[37] Lenaz G. Mitochondria and reactive oxygen species. Which role in physiology and pathology? Adv Exp Med Biol 2012; 942: 93-136.

[38] Drose S, Brandt U. Molecular mechanisms of superoxide production by the mitochondrial respiratory chain. Adv Exp Med Biol 2012; 748: 145-69.

[39] Chen Q, Vazquez EJ, Moghaddas S, Hoppel CL, Lesnefsky EJ. Production of reactive oxygen species by mitochondria: central role of complex III. J Biol Chem 2003; 278(38): 36027-31.

[40] Strolin Benedetti M, Tipton KF, Whomsley R, Baltes E. Factors affecting the relative importance of amine oxidases and monooxygenases in the in vivo metabolism of xenobiotic amines in humans. J Neural Transm 2007; 114(6): 787-91.

[41] Kaludercic N, Takimoto E, Nagayama T, et al. Monoamine oxidase A-mediated enhanced catabolism of norepinephrine contributes to adverse remodeling and pump failure in hearts with pressure overload. Circ Res 2010; 106(1): 193-202.

[42] Xu Q, Dalic A, Fang L, et al. Myocardial oxidative stress contributes to transgenic $\beta 2$-adrenoceptor activation-induced cardiomyopathy and heart failure. Br J Pharmacol 2011; 162(5): 1012-28.
[43] Lassegue B, San Martin A, Griendling KK. Biochemistry, physiology, and pathophysiology of NADPH oxidases in the cardiovascular system. Circ Res 2012; 110(10): 1364-90.

[44] Takac I, Schroder K, Zhang L, et al. The E-loop is involved in hydrogen peroxide formation by the NADPH oxidase Nox4. J Biol Chem 2011; 286(15): 13304-13.

[45] Kuroda J, Ago T, Matsushima S, et al. NADPH oxidase 4 (Nox4) is a major source of oxidative stress in the failing heart. Proc Natl Acad Sci USA 2010; 107(35): 15565-70.

[46] Sarma GN, Kinderman FS, Kim C, et al. Structure of D-AKAP2: PKA RI complex: insights into AKAP specificity and selectivity. Structure 2010; 18(2): 155-66.

[47] Cardone L, de Cristofaro T, Affaitati A, et al. A-Kinase Anchor Protein 84/121 are Targeted to Mitochondria and Mitotic Spindles by Overlapping Amino-terminal Motifs. J Mol Biol 2002; 320(3): 663-75.

[48] Livigni A, Scorziello A, Agnese S, et al. Mitochondrial AKAP121 links cAMP and src signaling to oxidative metabolism. Mol Biol Cell 2006; 17(1): 263-71.

[49] Feliciello A, Gottesman ME, Avvedimento EV. cAMP-PKA signaling to the mitochondria: protein scaffolds, mRNA and phosphatases. Cell Signal 2005; 17(3): 279-87.

[50] Lefkimmiatis K, Leronni D, Hofer AM. The inner and outer compartments of mitochondria are sites of distinct cAMP/PKA signaling dynamics. J Cell Biol 2013; 202(3): 453-62.

[51] Zima AV, Blatter LA. Redox regulation of cardiac calcium channels and transporters. Cardiovasc Res 2006; 71(2): 310-21.

[52] Mildaziene V, Baniene R, Nauciene Z, et al. Ca2+ stimulates both the respiratory and phosphorylation subsystems in rat heart mitochondria. Biochem J 1996; 320: 329 \pm 34 .

[53] Izem-Meziane M, Djerdjouri B, Rimbaud S, et al. Catecholamineinduced cardiac mitochondrial dysfunction and mPTP opening: protective effect of curcumin. Am J Physiol Heart Circ Physiol 2012; 302: H665-H74.

[54] Gordeeva AV, Zvyagilskaya RA, Labas YA. Cross-talk between reactive oxygen species and calcium in living cells. BIOCHEMISTRY (Moscow) 2003; 68(10): 107780.

[55] Tan S, Sagara Y, Liu Y, Maher P, Schubert D. The Regulation of Reactive Oxygen Species Production during Programmed Cell Death. J Cell Biol 1998; 141(6): 1423-32.

[56] Ganitkevich VY. The role of mitochondria in cytoplasmic $\mathrm{Ca} 2+$ cycling. Exp Physiol 2003; 88(1): 91-7.

[57] Kroemer G, Galluzzi L, Brenner C. Mitochondrial membrane permeabilization in cell death. Physiol Rev 2007; 87(1): 99-163.

[58] Lebiedzinska M, Karkucinska-Wieckowska A, Wojtala A, et al. Disrupted ATP synthase activity and mitochondrial hyperpolarisation-dependent oxidative stress is associated with p66Shc phosphorylation in fibroblasts of NARP patients. Int $\mathrm{J}$ Biochem Cell Biol 2013; 45(1): 141-50.

[59] Cosentino F, Francia P, Camici GG, et al. Final common molecular pathways of aging and cardiovascular disease: role of the p66Shc protein. Arterioscler Thromb Vasc Biol 2008; 28(4): 622-8.

[60] Balaban RS, Nemoto S, Finkel T. Mitochondria, oxidants, and aging. Cell 2005; 120(4): 483-95.

[61] Chen X, Piacentino V, 3rd, Furukawa S, et al. L-type Ca2+ channel density and regulation are altered in failing human ventricular myocytes and recover after support with mechanical assist devices. Circ Res 2002; 91(6): 517-24.

[62] Baartscheer A. Adenovirus gene transfer of SERCA in heart failure. A promising therapeutic approach? Cardiovasc Res 2001; 49(2): 249-52.

[63] Duchen MR. Mitochondria and calcium: from cell signalling to cell death. J Physiol 2000; 529 Pt 1: 57-68.

[64] Figueira TR, Barros MH, Camargo AA, et al. Mitochondria as a source of reactive oxygen and nitrogen species: from molecular mechanisms to human health. Antioxid Redox Signal 2013; 18(16): 2029-74.

[65] Andersson DC, Fauconnier J, Yamada T, et al. Mitochondrial production of reactive oxygen species contributes to the $\beta$ adrenergic stimulation of mouse cardiomycytes. J Physiol 2011; 589(Pt 7): 1791-801.

[66] Remondino A, Kwon SH, Communal C, et al. $\beta$-adrenergic receptor-stimulated apoptosis in cardiac myocytes is mediated by reactive oxygen species/c-Jun NH2-terminal kinase-dependent activation of the mitochondrial pathway. Circ Res 2003; 92(2): 136-8. 
[67] Menon B, Krishnamurthy P, Kaverina E, et al. Expression of the cytoplasmic domain of $\beta 1$ integrin induces apoptosis in adult rat ventricular myocytes (ARVM) via the involvement of caspase-8 and mitochondrial death pathway. Basic Res Cardiol 2006; 101(6): 485-93.

[68] Nagasaka S, Katoh H, Niu CF, et al. Protein kinase A catalytic subunit alters cardiac mitochondrial redox state and membrane potential via the formation of reactive oxygen species. Circ J 2007; 71(3): 429-36.

[69] Alp NJ, Channon KM. Regulation of endothelial nitric oxide synthase by tetrahydrobiopterin in vascular disease. Arterioscler Thromb Vasc Biol 2004; 24(3): 413-20.

[70] Lowenstein CJ. Nitric oxide regulation of protein trafficking in the cardiovascular system. Cardiovasc Res 2007; 75(2): 240-6.

[71] Sun J, Murphy E. Protein S-nitrosylation and cardioprotection. Circ Res 2010; 106(2): 285-96.

[72] Lima B, Forrester MT, Hess DT, Stamler JS. S-nitrosylation in cardiovascular signaling. Circ Res 2010; 106(4): 633-46.

[73] Piantadosi CA. Regulation of mitochondrial processes by protein S-nitrosylation. Biochim Biophys Acta 2012; 1820(6): 712-21.

[74] Ascensao A, Lumini-Oliveira J, Machado NG, et al. Acute exercise protects against calcium-induced cardiac mitochondrial permeability transition pore opening in doxorubicin-treated rats. Clin Sci (Lond) 2011; 120(1): 37-49.

[75] Fajardo G, Zhao M, Berry G, et al. $\beta 2$-adrenergic receptors mediate cardioprotection through crosstalk with mitochondrial cell death pathways. J Mol Cell Cardiol 2011; 51(5): 781-9.

[76] Traynham CJ, Roof SR, Wang H, et al. Diesterified Nitrone Rescues Nitroso-Redox Levels and Increases Myocyte Contraction Via Increased SR Ca(2+) Handling. PLoS One 2012; 7(12): e52005.

[77] Takimoto E, Kass DA. Role of oxidative stress in cardiac hypertrophy and remodeling. Hypertension 2007; 49(2): 241-8.

[78] Ni L, Zhou C, Duan Q, et al. $\beta$-AR blockers suppresses ER stress in cardiac hypertrophy and heart failure. PLoS One 2011; 6(11): e27294.

[79] Reiken S, Wehrens XH, Vest JA, et al. $\beta$-blockers restore calcium release channel function and improve cardiac muscle performance in human heart failure. Circulation 2003; 107(19): 2459-66.

[80] Yoo B, Lemaire A, Mangmool S, et al. $\beta 1$-adrenergic receptors stimulate cardiac contractility and CaMKII activation in vivo and enhance cardiac dysfunction following myocardial infarction. Am J Physiol Heart Circ Physiol 2009; 297(4): H1377-86.

[81] Ai X, Curran JW, Shannon TR, Bers DM, Pogwizd SM. $\mathrm{Ca} 2+/$ calmodulin-dependent protein kinase modulates cardiac ryanodine receptor phosphorylation and sarcoplasmic reticulum $\mathrm{Ca} 2+$ leak in heart failure. Circ Res 2005; 97(12): 1314-22.

[82] Okumura S, Vatner DE, Kurotani R, et al. Disruption of type 5 adenylyl cyclase enhances desensitization of cyclic adenosine monophosphate signal and increases Akt signal with chronic catecholamine stress. Circulation 2007; 116(16): 1776-83.

[83] Chen Z, Chua CC, Ho YS, Hamdy RC, Chua BH. Overexpression of Bcl-2 attenuates apoptosis and protects against myocardial I/R injury in transgenic mice. Am J Physiol Heart Circ Physiol 2001; 280(5): H2313-20.

[84] Wills LP, Trager RE, Beeson GC, et al. The $\beta 2$-adrenoceptor agonist formoterol stimulates mitochondrial biogenesis. J Pharmacol Exp Ther 2012; 342(1): 106-18.

[85] Huang C, Chen D, Xie Q, Yang Y, Shen W. Nebivolol stimulates mitochondrial biogenesis in 3T3-L1 adipocytes. Biochem Biophys Res Commun 2013; 438(1): 211-7.

[86] Carreira RS, Monteiro P, Gon Alves LM, Providencia LA. Carvedilol: just another $\beta$-blocker or a powerful cardioprotector? Cardiovasc Hematol Disord Drug Targets 2006; 6(4): 257-66.

[87] Oliveira PJ, Goncalves L, Monteiro P, Providencia LA, Moreno AJ. Are the antioxidant properties of carvedilol important for the protection of cardiac mitochondria? Curr Vasc Pharmacol 2005; 3(2): 147-58

[88] Oliveira PJ, Bjork JA, Santos MS, et al. Carvedilol-mediated antioxidant protection against doxorubicin-induced cardiac mitochondrial toxicity. Toxicol Appl Pharmacol 2004; 200(2): 159-68.

[89] Oliveira PJ, Esteves T, Rolo AP, Palmeira CM, Moreno AJ. Carvedilol inhibits the mitochondrial permeability transition by an antioxidant mechanism. Cardiovasc Toxicol 2004; 4(1): 11-20.

[90] Oliveira PJ, Rolo AP, Palmeira CM, Moreno AJ. Carvedilol reduces mitochondrial damage induced by hypoxanthine/xanthine oxidase: relevance to hypoxia/reoxygenation injury. Cardiovasc Toxicol 2001; 1(3): 205-13

[91] Oliveira PJ, Rolo AP, Sardao VA, et al. Carvedilol in heart mitochondria: protonophore or opener of the mitochondrial K(ATP) channels? Life Sci 2001; 69(2): 123-32.

[92] Oliveira PJ, Marques MP, Batista de Carvalho LA, Moreno AJ. Effects of carvedilol on isolated heart mitochondria: evidence for a protonophoretic mechanism. Biochem Biophys Res Commun 2000; 276(1): 82-7.

[93] Oettl K, Greilberger J, Zangger K, et al. Radical-scavenging and iron-chelating properties of carvedilol, an antihypertensive drug with antioxidative activity. Biochem Pharmacol 2001; 62(2): 2418 .

[94] Sgobbo P, Pacelli C, Grattagliano I, Villani G, Cocco T. Carvedilol inhibits mitochondrial complex I and induces resistance to $\mathrm{H} 2 \mathrm{O} 2$ mediated oxidative insult in $\mathrm{H} 9 \mathrm{C} 2$ myocardial cells. Biochim Biophys Acta 2007; 1767(3): 222-32.

[95] $\mathrm{Xu} \mathrm{C}, \mathrm{Hu} \mathrm{Y}, \mathrm{Hou} \mathrm{L}$, et al. $\beta$-blocker carvedilol protects cardiomyocytes against oxidative stress-induced apoptosis by up-regulating miR-133 expression. J Mol Cell Cardiol 2014; 75C: 111-21.

[96] Yeh CH, Chen TP, Wang YC, Lin YM, Fang SW. Carvedilol treatment after myocardial infarct decreases cardiomyocytic apoptosis in the peri-infarct zone during cardioplegia-induced cardiac arrest. Shock 2013; 39(4): 343-52.

[97] Albert NM, Eastwood CA, Edwards ML. Evidence-based practice for acute decompensated heart failure. Crit Care Nurse 2004; 24(6): 14-6, 8-24, 6-9; quiz 30-1. 